\title{
LEVANTAMENTO DA COBERTURA FLORESTAL NATURAL DA MICRORREGIÃO DE VIÇOSA, MG, UTILIZANDO-SE IMAGENS DE LANDSAT $5^{1}$
}

Danilo José da Silva Coelho², Agostinho Lopes de Souza ${ }^{3}$ e Cláudia Maria Lourenço de Oliveira ${ }^{4}$

\begin{abstract}
RESUMO - Este trabalho aborda o levantamento da cobertura florestal natural da microrregião de Viçosa, MG, realizado em 1998, utilizando-se imagens do Landsat 5. Verificou-se que: a) a cobertura florestal natural abrange 57.310 ha $(24,27 \%$ da área total), dos quais $24.184,80$ ha $(10,24 \%)$ correspondem a mata e $33.125,31$ $(14,03 \%)$ a capoeira; b) os municípios que possuem cobertura florestal natural abaixo de $20 \%$ são Cajuri, Coimbra, Canaã e São Miguel do Anta e os acima de 20\%, Pedra do Anta, Ervália, Viçosa, Paula Cândido, Teixeiras, Porto Firme e Araponga; c) Cajuri é o município com a menor taxa de crescimento florestal e Araponga, com a maior; d) Araponga é o município com a maior área florestal e Coimbra, com a menor; e e) a área de cobertura florestal natural teve incremento de 13,60\%, de 1994 a 1998.
\end{abstract}

Palavras-chave: Levantamento, técnicas de sensoriamento remoto e cobertura florestal natural.

\section{NATURAL FOREST COVER SURVEY OF THE MICROREGION OF VIÇOSA, MG, BRAZIL, USING LANDSAT 5 IMAGES}

\begin{abstract}
This work was carried out to survey the natural forest cover of the microregion of Viçosa-MG, Brazil, in 1998, using Landsat 5 images. It was found that: a) the natural forest cover comprises 57,310 ha (24.27\% of the total area), from which 24,184.80 ha (10.24\%) correspond to forest and 33,125.31 ha (14.03\%) correspond to "(young secondary forest); $b$ ) the municipalities that have a natural forest cover below 20\% are Cajuri, Coimbra, Canaã and São Miguel do Anta, and those with a cover above 20\% are Pedra do Anta, Ervália, Viçosa, Paula Cândido, Teixeiras, Porto Firme and Araponga; c) Cajuri is the municipality with the smallest growth ratein forest area and Araponga has the greatest growth rate; $d)$ Araponga is the municipality with the greatest forest area and Coimbra has the smallest one, and e) the natural forest cover area had an increment of $13.60 \%$ from 1994 to 1998.
\end{abstract}

Key words: Survey, remote sensing techniques and natural forest cover.

\footnotetext{
${ }^{1}$ Recebido em 07.11.2003 e aceito para publicação em 25.11.2004.

${ }^{2}$ Engenheiro Florestal, CEDEF-IEF, Vila Gianetti 51, Universidade Federal de Viçosa - UFV, 36570-000 Viçosa,MG.

${ }^{3}$ Departamento de Engenharia Florestal - UFV. E-mail: <alsouza@ufv.br>.

${ }^{4}$ Bióloga, CEDEF- IEF, Vila Gianeti 51 - UFV.
} 


\section{INTRODUÇÃO}

A utilização sustentável de bens e serviços da floresta, como a exploração de madeira; a conservação da biodiversidade; a proteção dos recursos hídricos, edáficos e faunísticos; a elevação da renda "per capita"; e a melhoria da qualidade de vida, é um desafio a ser superado pela sociedade brasileira.

A degradação ambiental causada pela pressão do crescimento populacional e econômico do país, aliada à inexistência de uma política de gerenciamento dos recursos naturais, recomenda uma série de atividades consideradas essenciais para encontrar os caminhos do desenvolvimento sustentável e o manejo adequado desses recursos ainda existentes.

Os responsáveis pela implementação de estratégias de governo e pela elaboração de planejamentos regionais necessitam dispor de informações básicas sobre os recursos naturais, a fim de estabelecer uma política eficiente de controle e direcionamento das ações antrópicas, de fundamental importância ao desenvolvimento da economia e à melhor qualidade de vida.

A implementação de uma correta política ambiental requer o conhecimento da distribuição espacial desses recursos, o que pode ser obtido através do mapeamento em épocas diferentes.

Este trabalho de gestão e controle dos recursos naturais com base em princípios de sustentabilidade teve como objetivo identificar, caracterizar e quantificar a base de recursos florestais existentes em 1998, em comparação com 1994.

\section{MATERIAL E MÉTODOS}

\section{1. Área de estudo}

A microrregião de Viçosa, composta pelos municípios de Araponga, Cajuri, Canaã, Coimbra, Ervália, Paula Cândido, Pedra do Anta, Porto Firme, São Miguel do Anta, Teixeiras e Viçosa, localiza-se na região da Zona da Mata, no sudeste de Minas Gerais, entre as coordenadas geográficas de $20^{\circ} 28^{\prime}$ e $21^{\circ} 20^{\prime}$ da latitude sul e $42^{\circ} 20^{\prime}$ e $43^{\circ} 13^{\prime}$ de longitude oeste (Figura 1).

A região é embasada em rochas gnáissicas do précambiano, apresentando relevo dominantemente forte ondulado e montanhoso (Mar de Morros), com encostas de perfil convexo-côncavo embutido em vales de fundo chato, formados por terraços e leitos maiores, onde meandram cursos d'água pouco expressivos (CORRÊA, 1984). Duas unidades da paisagem se destacam na região: as elevações, com encostas íngremes ou suaves, e as baixadas. Nas elevações predominam os Latossolos Vermelho-Amarelos (seções convexas) e os cambissolos (seções côncavas) e nas baixadas, os podzólios e os aluviais (RESENDE, 1982; RESENDE et al., 1997).

O clima é do tipo $\mathrm{Cwb}$, tropical de altitude, com verões chuvosos e invernos frios e secos, temperatura média mensal anual oscilando de 20 a $22^{\circ} \mathrm{C}$ e precipitação média anual de 1.221,4 mm (MEIRA NETO, 2002).

As formações florestais existentes incluem-se no domínio da Mata Atlântica (Floresta Estacional Semidecidual), nos estágios primário e secundário, sujeitas a um ritmo estacional, com 20 a 50\% de árvores caducifólias na época desfavorável (estação seca) (VELOSO et al.,1991). O tipo de formação é submontana e montana, com limite altitudinal de $750 \mathrm{~m}$, nas latitudes entre 16 e $24^{\circ} \mathrm{S}$, adotado por Oliveira-Filho et al. (1994).

\subsection{Levantamento da base dos recursos florestais naturais disponíveis na microrregião de Viçosa, MG}

O diagnóstico da situação da cobertura vegetal natural e do uso da terra na microrregião de Viçosa, no ano de 1994 e 1998, foi feito com base no "Documento Zero" (mapas digitais) e imagens do satélite Landsat 5.

O "Documento Zero" consistiu no levantamento da cobertura vegetal e do uso da terra do Estado de Minas Gerais, realizado através do convênio entre o Instituto Estadual de Florestas - IEF/MG e o Consórcio Funcate/Imagem, a partir do ano de 1993, utilizando técnicas de sensoriamento remoto e sistema de informações geográficas (SIG), com o objetivo principal de mapeamento e implantação de um sistema de monitoramento dos remanescentes florestais.

De posse desses arquivos digitais e com a implantação de um programa de monitoramento, o IEF/ MG passou a monitorar e atualizar os dados de cobertura florestal natural do Estado, a fim de subsidiar trabalhos de planejamentos florestal e ambiental, entre outros.

Além das técnicas de sensoriamento remoto e geoprocessamento, foram executados trabalhos de campo, coleta de dados e revisões bibliográficas, que permitiram uma descrição mais acurada da tipologia mapeada e uma visão integrada da microrregião. 


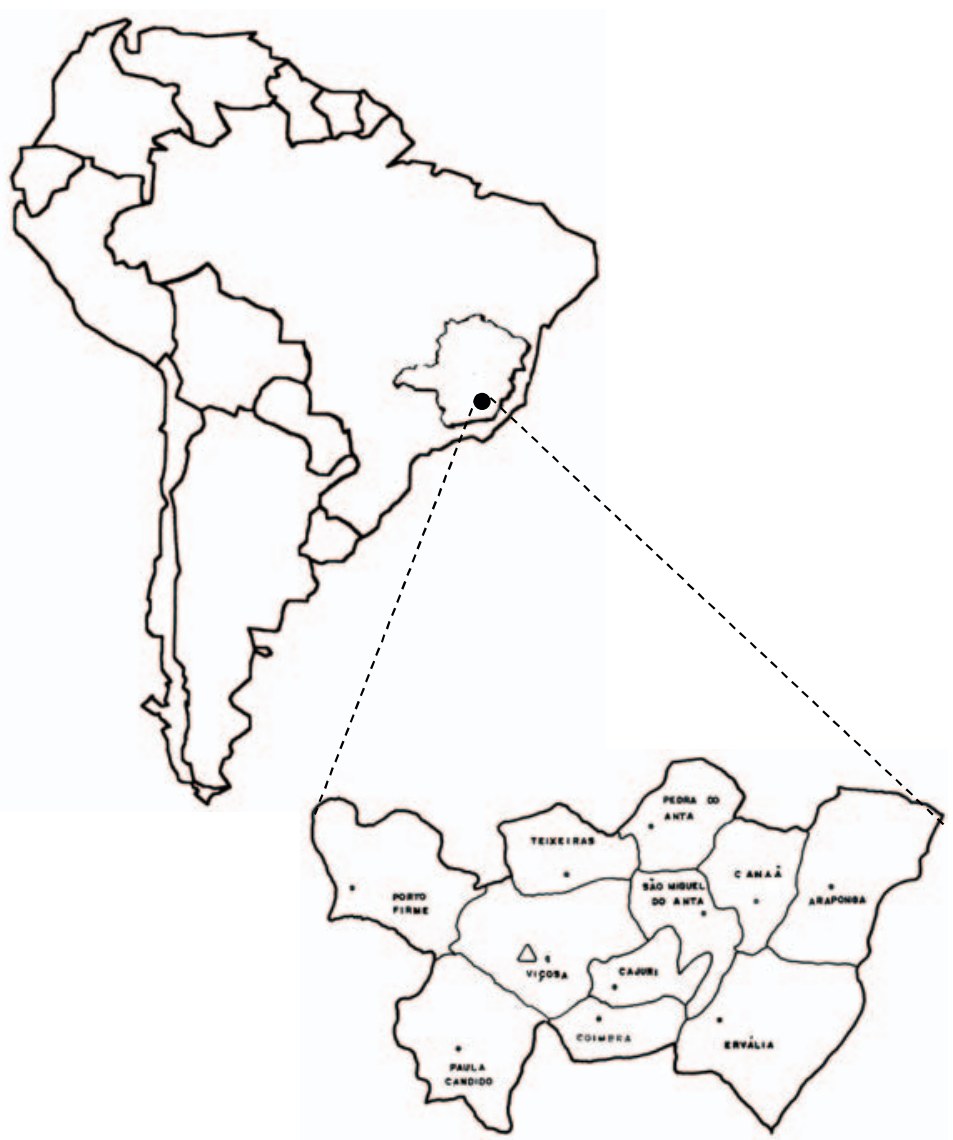

Figura 1 - Mapa da América do Sul, destacando-se o Estado de Minas Gerais e a microrregião de Viçosa. Figure 1 - Map of South America, showing the State of Minas Gerais and the microregion of Viçosa.

As discrepâncias das áreas de cobertura florestal natural nos municípios da microrregião de Viçosa foram avaliadas pela taxa de incremento, cujo cálculo foi feito através da fórmula $T I=\left(\frac{A_{1}}{A_{0}}-1\right) \times 100$, em que $\mathrm{A}_{1}$ é a área existente em 1998 e $\mathrm{A}_{0}$ em 1994. Os valores positivos indicam aumento de áreas de cobertura florestal natural, os negativos diminuição e os nulos estabilidade.

\subsection{Imagens orbitais}

Utilizaram-se, para o levantamento da cobertura florestal natural e do uso da terra, imagens do sensor Thematic Mapper (TM), que está a bordo do satélite Landsat-5, mais precisamente a cena 217-74, em seus quadrantes C e D, adquirida em 1998, no INPE.

\subsection{Equipamentos utilizados}

- Mesa de luz.

- Estação de trabalho SITIM/SGI completa.

- Monitor colorido de alta resolução.

- Placa gráfica com processador TMS 3410 e TMS 34020.

- Mesa digitalizadora tamanho A1.

- Software SPRING (tecnologia INPE).

- "Scanner" com resolução de 600 dpi.

- Plotter eletrostático VERSATEC e jato de tinta HP650C.

- GPS.

- Traçadores gráficos de precisão. 


\section{RESULTADOS E DISCUSSÃO}

\subsection{Cobertura florestal natural e uso da terra no ano de 1998}

Na Figura 2 e no Quadro 1 são apresentados a distribuição dos tipos de cobertura florestal natural e outros usos em 1998.

A região apresenta $74,40 \%$ da área total ocupada por pastagens e agricultura, 24,29\% com cobertura florestal nativa, e 1,33\% com outros usos. Da área total de florestas nativa, $24.034,13$ ha são de mata primária $(42,0 \%)$, sendo o restante de capoeira, ou seja, vegetação secundária $(58,0 \%)$, indicando alto grau de degradação provocado por ações antrópicas dos ciclos do café e da pecuária principalmente (Figura 3).

\subsection{Uso da terra e cobertura florestal natural nos anos de 1994 e 1998}

Comparando o diagnóstico de uso da terra de 1994 obtido por Coelho e Souza (2002), no qual 74,65\% da área total se encontrava ocupada com pastagens e agricultura; $23,04 \%$ com cobertura florestal natural; e $2,31 \%$ com outros usos, com o ano de 1998 , verificou-se aumento nas áreas de cobertura florestal natural em $2,80 \%$ e uma diminuição das áreas de pastagens em $3,10 \%$ (Figura 4).

Provavelmente aumento da cobertura florestal na microrregião se deve principalmente às restrições legais impostas pelo Decreto Federal 750, de 10 de fevereiro de 1993, em que o corte, a exploração e a supressão da vegetação primária ou nos estágios de avançado e médio de regeneração foram proibidos, aliados a outros fatores, como fiscalização eficiente do IEF/POLICIAAMBIENTALe, em alguns casos, abandono de áreas de pastagens degradadas em função da declividade acentuada e baixa fertilidade dos solos.

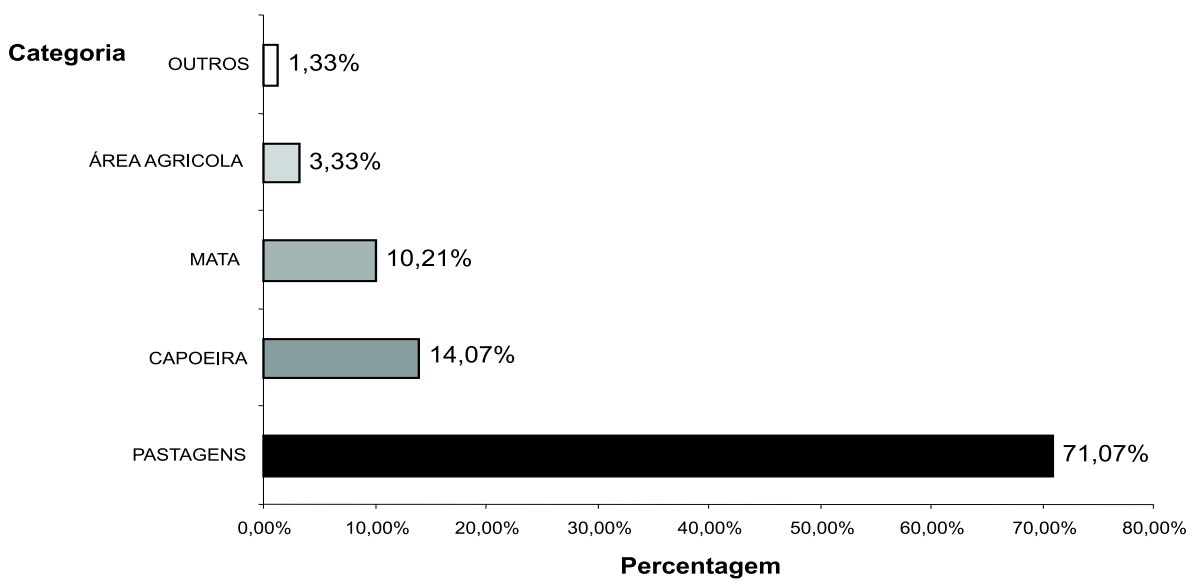

Figura 2 - Cobertura vegetal natural e uso da terra, em porcentagem, na microrregião de Viçosa, no ano de 1998. Figure 2 -Vegetal cover and land use in percentage, in the microregion of Viçosa, in the year 1998.

Quadro 1 - Uso da terra e cobertura florestal natural na microrregião de Viçosa, nos anos de 1994 e 1998 Table 1 - Land use and native forest cover in the microregion of Viçosa in the years 1994 and 1998

\begin{tabular}{lrrrrr}
\hline Categoria & Uso $1994(\mathrm{ha})$ & Uso $1994(\%)$ & Uso 1998 (ha) & Uso $1998(\%)$ & Diferença (ha) \\
\hline Área agrícola & $7.536,60$ & 3,20 & $7.832,70$ & 3,32 & 10,24 \\
Mata & $22.366,08$ & 9,50 & $24.184,80$ & $1.818,72$ \\
Capoeira & $28.083,15$ & 11,92 & $33.125,31$ & $5.042,16$ \\
Pastagens & $174.126,51$ & 73,94 & $166.706,37$ & $-7.420,14$ \\
Outros & $3.389,94$ & 1,44 & $3.653,10$ & 1,55 \\
Total & $235.502,28$ & 100,00 & $235.502,28$ & 100,00 \\
\hline
\end{tabular}

R. Árvore, Viçosa-MG, v.29, n.1, p.17-24, 2005 


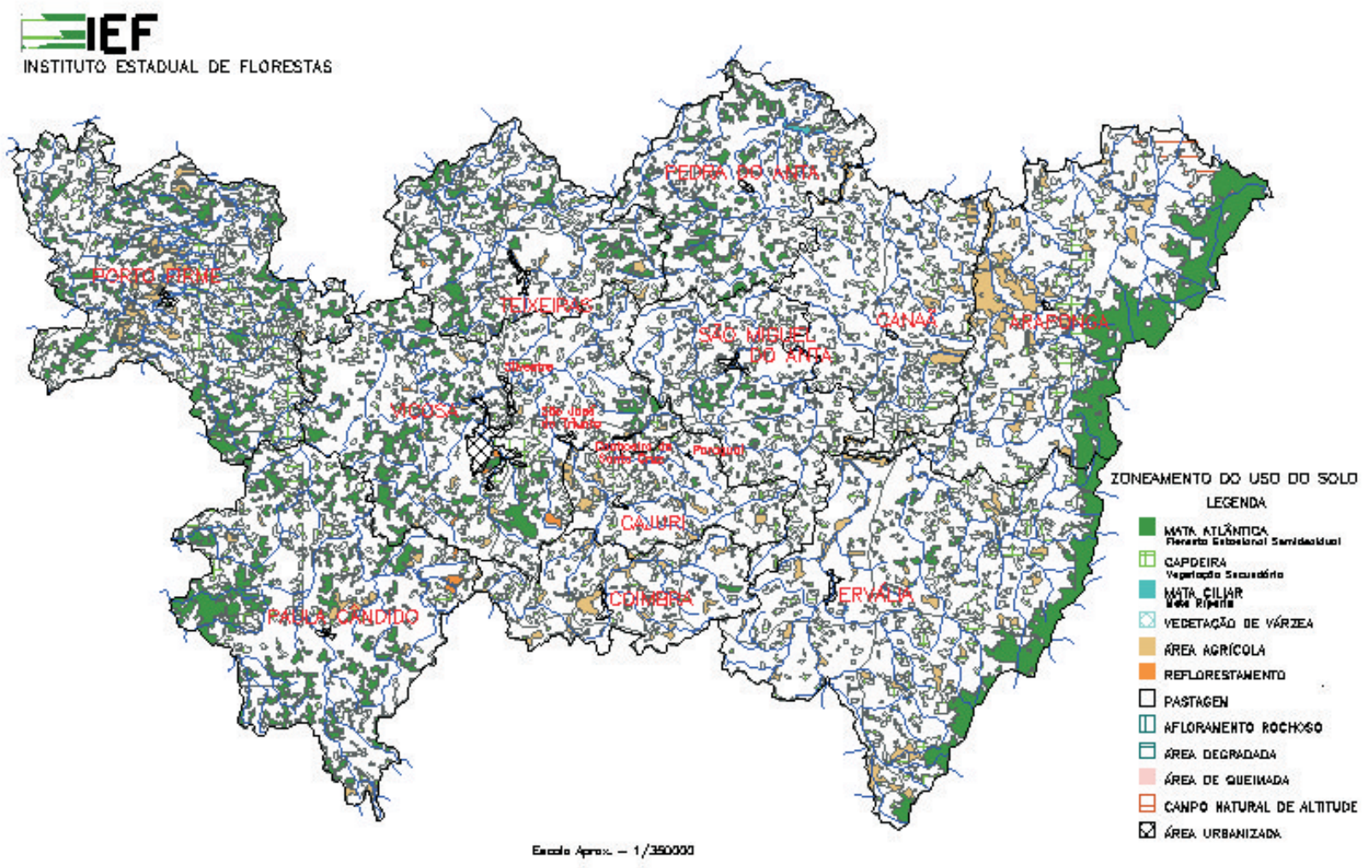

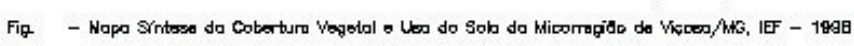

Figura 3 - Mapa-síntese da cobertura vegetal e uso da terra da microrregião de Viçosa, MG, no ano de 1998. Figure 3 - Map synthesis of plant cover and land use in the microregion of Viçosa-MG, in the year 1998.

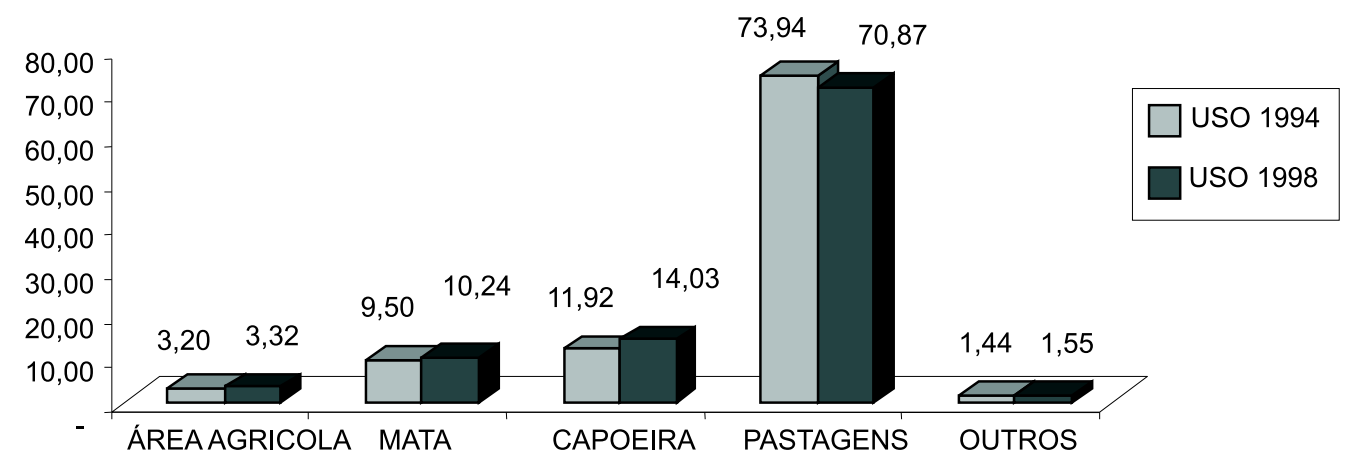

Figura 4 - Porcentagem do uso da terra na microrregião de Viçosa, MG, no ano de 1994-1998. Figure 4-Percentage of land use in the microregion of Viçosa, MG, in the years 1994-1998. 


\subsection{Formações florestais naturais, por município, no ano de 1998}

A cobertura florestal original da microrregião de Viçosa insere-se no domínio da Mata Atlântica (Floresta Estacional Semidecidual) (IEF, 1994).

A cobertura florestal remanescente, em sua maioria localizada em áreas de difícil acesso e relevo acidentado, geralmente em áreas de preservação permanente, concentra-se em pequenas propriedades particulares, com predominância de capoeiras (vegetação secundária).

A análise de imagens do Landsat 5 indicou que o município de Araponga possui a maior porcentagem de cobertura florestal natural $(34,49 \%)$, seguido dos municípios de Porto Firme (32,83\%) e Teixeiras (28,98\%); os municípios de Cajuri (11,35\%), Coimbra (14,58\%) e Canaã $(14,84 \%)$ apresentaram cobertura florestal natural abaixo do mínimo exigido pela legislação florestal e que, da área total $(235.502,28$ ha), apenas 57.160,44 ha $(24,27 \%)$ são florestas naturais (Figura 5).

A maior cobertura florestal natural do município de Araponga se deve, principalmente, à ocorrência de relevo mais acidentado e solos com afloramento rochoso o que dificulta a exploração florestal e o uso de práticas agropastoris. O município de Cajuri apresenta um relevo mais plano, facilitando o uso da terra para práticas agropecuárias concorrendo com áreas de cobertura florestal natural.

Ao comparar dados de cobertura florestal natural existente em 1994 com os de 1998, observou-se que a menor taxa de incremento ocorreu no município de Cajuri $(0,34 \%)$ e a maior, no município de Porto Firme $(22,40 \%)$, resultando num acréscimo de $13,60 \%$ em relação a 1994 (Quadro 2 e Figura 6).

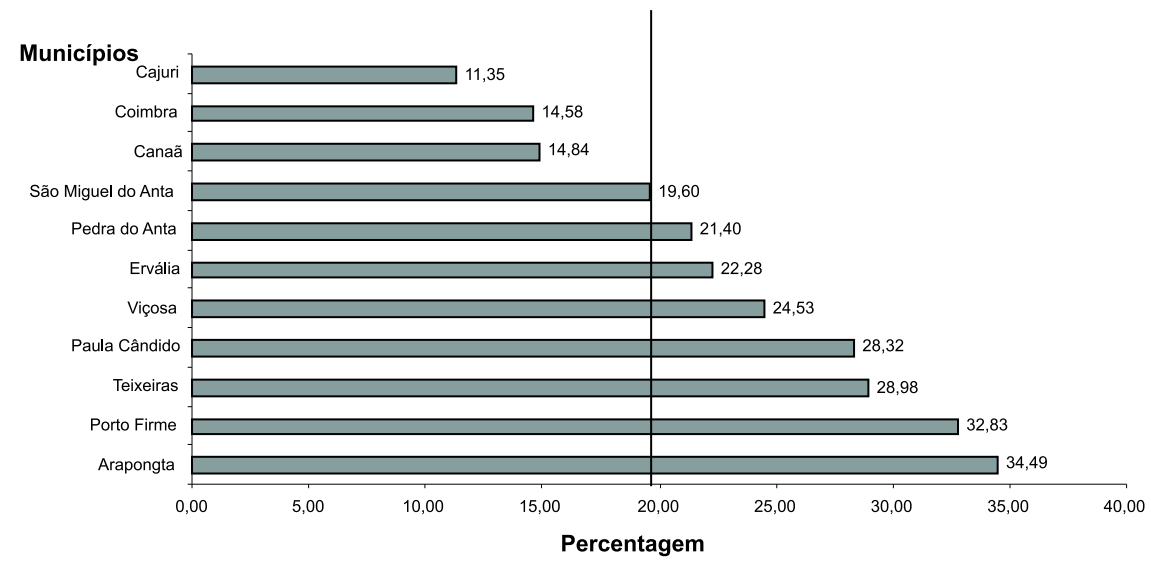

Figura 5 - Porcentagem de cobertura florestal natural, por município, na microrregião de Viçosa, no ano de 1998. Figure 5 - Porcentage of native forest cover, by municipality, in the microregion of Viçosa, in the year 1998.

Quadro 2 - Cobertura florestal natural e taxa de incremento em área por município, na microrregião de Viçosa, Minas Gerais, no período de 1994 a 1998

Table 2 - Native forest cover and increment rate in area, by municipality, in the microregion of Viçosa, Minas Gerais, between 1994 and 1998

\begin{tabular}{lccc}
\hline Municípios & Ano $1994($ ha $)$ & Ano $1998($ ha $)$ & Incremento em área $(\%)$ \\
\hline Porto Firme & $7.653,51$ & $9.355,86$ & 22,40 \\
Paula Cândido & $5.960,07$ & $7.277,40$ & 22,10 \\
Araponga & $8.828,28$ & $10.347,21$ & 17,21 \\
Pedra do Anta & $2.903,85$ & $3.337,83$ & 14,94 \\
Coimbra & $1.158,21$ & $1.326,87$ & 14,56 \\
Ervália & $6.914,88$ & $7.752,51$ & 12,11 \\
Teixeiras & $3.745,08$ & $4.028,04$ & 7,56 \\
Viçosa & $6.453,72$ & $6.844,86$ & 6,06 \\
São Miguel do Anta & $2.631,24$ & $2.763,63$ & 5,03 \\
Canaã & $2.764,17$ & $2.834,73$ & 2,55 \\
Cajuri & $1.436,22$ & $1.441,17$ & 0,34 \\
Total & $50.449,23$ & $57.310,11$ & 13,60 \\
\hline
\end{tabular}

R. Árvore, Viçosa-MG, v.29, n.1, p.17-24, 2005 


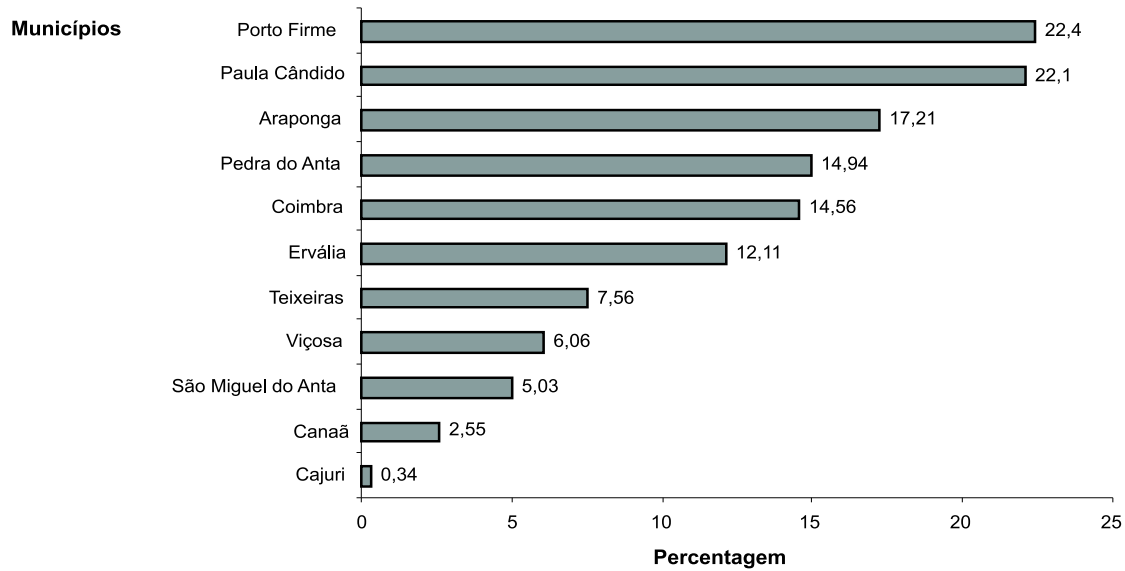

Figura 6 - Taxa de incremento em área de cobertura florestal natural por município da microrregião de Viçosa, Minas Gerais, no período de 1994 a 1998.

Figure 6 - Forest cover increment rate in area, by municipalities of the microregion of Viçosa, Minas Gerais, between 1994 and 1998.

\section{CONCLUSÕES}

A partir dos resultados, chegou-se às seguintes conclusões:

a) A cobertura florestal natural da microrregião de Viçosa abrange 50.445,25 ha, ou seja, 21,42\% da área total.

b) Os municípios com menos de $20 \%$ de cobertura florestal natural são Cajuri, Coimbra, Canaã e São Miguel do Anta e os com mais de 20\%, Pedra do Anta, Ervália, Viçosa, Paula Cândido, Teixeiras, Porto Firme e Araponga.

c) Cajuri é o município com menor taxa de incremento de área florestal natural e Porto Firme, o de maior.

d) Araponga é o município que apresentou a maior área de cobertura florestal natural e Coimbra, a menor.

e) No período de 1994 a 1998 ocorreu aumento de áreas com cobertura florestal natural de 13,6\%.

\section{REFERÊNCIAS BIBLIOGRÁFICAS}

COELHO, D.J.S.; SOUZA, A. L. Modelo de gestão florestal sustentável para microrregião de Viçosa, Minas Gerais. Revista Árvore, v.26, n.2, p.145-154, 2002.
CORRÊA, G. F. Modelo de evolução e mineralogia da fração argila de solos do Planalto de Viçosa. 1984. $87 \mathrm{f}$. Dissertação (Mestrado em Solos e Nutrição de Plantas) - Universidade Federal de Viçosa, Viçosa, 1984.

INSTITUTO ESTADUAL DE FLORESTAS-IEF. Contrato BIRD/ SEPLAN/IEF-MG. Programa Prófloresta. Cobertura vegetal e uso do solo do Estado de Minas Gerais. Belo Horizonte: 1994. 1 mapa: color. 99x66. Escala: 1:1.500.000. Material cartográfico.

MEIRA-NETO, J.A.A.; MARTINS, F.R.

Composição florística de uma floresta estacional semidecidual Montana no município de ViçosaMG. Revista Árvore, v.26, n.4, p.437-446, 2002.

OLIVEIRA-FILHO, A.T. et al. Comparison of the woody flora and soils of six áreas of montane semideciduous forests in southern Minas Gerais, Brazil. Edinburgh Journal of Botany, v.51, p.141-194, 1994.

RESENDE, M. Pedologia. Viçosa, MG: Universidade Federal de Viçosa, 1982. 100p.

RESENDE, M. et. al. Pedologia: base para distinção de ambientes. 2. ed. Viçosa: Jard Produções, 1997. 367p.

R. Árvore, Viçosa-MG, v.29, n.1, p.17-24, 2005 
RESOLUÇÃO CONAMA No 10, ANO 1993. Estabelece os parâmetro básicos para análise dos estágios de sucessão de Mata Atlântica. Data da legislação: 01/10/ 1993. Publicada no DOU: 03/11/1993.
VELOSO, H. H.; RANGEL FILHO, A. L. R.; LIMA J. C. A. Classificação da vegetação brasileira adaptada a um sistema universal. Rio de janeiro: Instituto Brasileiro de Geografia e Estatística, 1991. 124p. 